\title{
Associations between sedentary behaviour patterns and depression among people aged 60 and older in Hebei Province of China
}

\author{
Jiaqi Wang ${ }^{1}$, Ruiqiang $\mathrm{Li}^{1}$, Limin Zhang ${ }^{1}$, Xian Gao ${ }^{1}$, Meiqi Zhou ${ }^{1}$, Xinjing Zhang ${ }^{2}$ and Yuxia Ma ${ }^{\text {* }}$
}

\begin{abstract}
Background: Sedentary behaviours (SBs) are now considered a risk factor for depression. Older adults are sedentary most of the time and are at a high risk of depression. However, not all types of SBs have adverse effects on mental health. Passive SBs (such as watching TV) increase the risk of depression, whereas mentally active SBs (such as using the internet and reading) decrease the risk of depression. The aim of this study was to explore the associations between type of SBs (i.e., passive and mentally active SBs) and depression among people aged 60 years and older in the Hebei Province of China.

Methods: This cross-sectional study used data from the baseline survey of the Community-based Cohort Study on Nervous System Diseases. A total of 2679 older adults aged $\geq 60$ years from the Hebei Province of China were included in this study. The type and time spent on SBs were self-reported. Watching TV was defined as a passive SB, whereas internet use, reading, and social SBs (including communicating with others and playing chess) were defined as mentally active SBs. Depression was evaluated using the Geriatric Depression Scale. The maximal possible score was 30 points, and $\geq 11$ points indicated depression. Logistic regression analysis was used to assess the relationship between SBs and depression. Covariates included sex, age, education, employment, smoking, alcohol consumption, sleep duration, domestic work, physical exercise, body mass index (BMI), and chronic diseases.

Results: At baseline, the participants who spent two or more hours and $0 \mathrm{~h}$ on passive SBs (i.e., TV viewing) had a greater risk of depression ( $=0 \mathrm{~h}$ : adjusted $\mathrm{OR}=2.09,95 \% \mathrm{Cl}=1.18-3.76 ; 2-3 \mathrm{~h}: \mathrm{OR}=2.21,95 \% \mathrm{Cl}=1.16-4.16$; $>3 \mathrm{~h}$ : $\mathrm{OR}=3.59,95 \% \mathrm{Cl}=1.93-6.68$ ) than the participants who spent $1-2 \mathrm{~h}$ on passive SBs. The participants who spent $>1 \mathrm{~h}$ on mentally active $\mathrm{SBs}$ had a lower risk of depression (adjusted $\mathrm{OR}=0.26,95 \% \mathrm{Cl}=0.06-0.71$ ) than the participants who did not engage in mentally active SBs. Not all mentally active SBs were linked to depression. The participants who engaged in social SBs had a lower risk of depression (adjusted OR: $0.24,95 \%$ Cl: $0.06-0.66$ ) than the participants who did not engage in social SBs.
\end{abstract}

Conclusions: Spending $2 \mathrm{~h}$ or more per day on passive SBs (watching TV) was associated with a high risk of depression among people aged 60 years and older in the Hebei Province of China. Mentally active SBs (predominantly social SBs) could reduce the risk of depression. Some participants with depression probably did not watch TV. These findings suggested that spending more time on social SBs (such as communicating with others and playing chess) rather than

\footnotetext{
*Correspondence: mayuxia@hebmu.edu.cn

1 Department of Nutrition and Food Hygiene, School of Public Health,

Hebei Medical University, Hebei Province Key Laboratory of Environment

and Human Health, Shijiazhuang, China

Full list of author information is available at the end of the article
} original author(s) and the source, provide a link to the Creative Commons licence, and indicate if changes were made. The images or other third party material in this article are included in the article's Creative Commons licence, unless indicated otherwise in a credit line to the material. If material is not included in the article's Creative Commons licence and your intended use is not permitted by statutory regulation or exceeds the permitted use, you will need to obtain permission directly from the copyright holder. To view a copy of this licence, visit http://creativecommons.org/licenses/by/4.0/. The Creative Commons Public Domain Dedication waiver (http://creativeco mmons.org/publicdomain/zero/1.0/) applies to the data made available in this article, unless otherwise stated in a credit line to the data. 
watching TV may have important public health implications for preventing and managing depression among older Chinese adults. Moreover, society should attend to the mental health of elderly adults who do not watch TV as they may be more prone to suffer from depressive symptoms.

Keywords: Depression, Passive sedentary behaviours, Mentally active sedentary behaviours, Older adults

\section{Introduction}

Years lived with disability from depression disorders have increased from $9.3 \%$ in 1990 to $37.5 \%$ in 2010 worldwide due to population growth and ageing [1]. According to the World Health Organization, in 2015, more than 300 million people had depression, and this value was equivalent to $4.4 \%$ of the world's population [2]. Older adults, especially those aged 55-74years, have a high incidence of depression, with prevalence rates of more than $7.5 \%$ in females and $5.5 \%$ in males [2]. Depression is known to lead to health problems, such as coronary atherosclerosis, diabetes, and metabolic syndrome [3-5].

Sedentary behaviours (SBs) are defined as any waking behaviour characterized by an energy expenditure of 1.5 metabolic equivalents (METs) while in a sitting or reclining posture [6]. Evidence has shown that older men and women spend nearly $70 \%$ [7] and 65\% [8], respectively, of their days on SBs. SBs are a strong risk factor for cardiovascular disease [9], type 2 diabetes [10], cancer [11, $12]$, and all-cause mortality $[13,14]$ and can cause many psychological problems, such as depression $[15,16]$ and anxiety $[17,18]$. A small number of studies have demonstrated a positive relationship between total sedentary time and depression in older adults [19-23].

However, whether all types of SBs increase the risk of depression remains unknown. A cross-sectional study including 24,060 participants found that substituting passive SBs (such as watching TV) with mentally active SBs (such as office work) may reduce depression risk in adults [24]. A 13-year cohort study also concluded that participants who spent $\geq 3 \mathrm{~h}$ per day on mentally active SBs (such as sitting in a meeting and knitting/ sewing) had a significantly lower risk of major depression than those who spent $<3 \mathrm{~h}$ per day on mentally active SBs $(p=0.018)$, [25]. In addition, other studies have reported that internet use and reading provide benefits against depression [26, 27]. One possible mechanism for this difference is that internet use represents improved social interaction [28] and minimizes loneliness [29], whereas watching TV is associated with loneliness [30]. Nevertheless, the classification of passive and mentally active SBs is not precise. Some studies have suggested that watching TV is classified as a passive SB while using computers and reading are classified as mentally active SBs [24, 31, 32].
While a few studies have examined the association of different SBs with depression in aged adults, these findings have been contradictory or mixed [32-37]. Several studies have reported that watching TV [32, 33] increases the risk of depression in senior adults. However, two other studies did not find that prolonged TV watching increased the risk of depression $[34,35]$. The lack of significance of these results may be attributed to the small sample sizes (i.e., 1383 [34] and 307 [35]) in these two studies. In contrast, two other studies found that watching TV protected against depression [36, 37]. However, a Nepalese study looked at TV watching TV and radio listening as a whole and could not determine which activity reduced the risk of depression. In addition, unlike in other countries, Nepal has more religious TV programs, which are popular with people [38]. Religion may be good for mental health in Nepal, but prolonged TV watching does not necessarily decrease the risk of depression. Another study included only 252 participants in a community of Taichung City [37]. This study found that watching TV on weekends reduced the risk of depression. However, the sample size was too small to be representative.

Only three studies examined the relationship between mentally active SBs and depression in older adults, but these studies had some problems [32, 33, 37]. One study found that older adults using the internet had lower depressive symptoms than those who did not engage in this activity, but reading the newspaper was not associated with depressive symptoms [33]. Andrade-Gomez et al. looked at reading, using the computer, and commuting and studied their relationship with depression as a whole rather than exploring their separate effects [32]. The third study, which examined the relationships between three mentally positive activities (reading newspapers and magazines, listening to radio, and engaging with internet) and depression, included only 252 participants [37].

In China, a meta-analysis showed that the pooled prevalence of depressive symptoms in elderly adults aged $\geq 60$ years was $23.6 \%(95 \% \mathrm{CI}=20.3-27.2 \%)$ and has increased steadily from 1987 to 2012 [39]. The total sedentary time of older Chinese adults increased by $0.58 \mathrm{~h}$ per day from 2002 to 2012 [40]. It is essential to clarify the relationship between SBs and depression in older Chinese adults. However, studies on the 
relationship between SBs and depression in elderly Chinese individuals are unavailable. Moreover, how different SBs affect depression in older adults remains unclear. Accordingly, the aim of the present study was to explore the associations between SBs (passive and mentally active SBs) and depression in people aged 60 years and older in the Hebei Province of China. Second, to explore whether different mentally positive SBs increased the risk of depression, we analysed the relationships between depression and using the internet, reading, and other SBs.

\section{Methods}

\section{Study design and participants}

The study used data from the Community-based Cohort Study on Nervous System Diseases (No. 2017YFC0907701) [41-43], a population-based longitudinal survey designed to establish community population cohorts of individuals with epilepsy, Alzheimer's disease (AD), and Parkinson's disease (PD); to explore disease risk factors; and to provide the scientific basis for realizing effective three-level prevention strategies at the community and individual levels. This study included participants aged $>1$ year without epilepsy or aged $\geq 55$ years without $\mathrm{AD}$ and $\mathrm{PD}$. The survey selected sites in Hebei, Zhejiang, Shanxi, and Hunan provinces. Two cities and two counties in each province were randomly selected. Urban and suburban neighbourhoods within cities and townships and villages within counties were randomly chosen. Volunteers and their families took part in the survey at each site, and those who did not meet the requirements based on the inclusion criteria were excluded.

This cross-sectional study used data from the baseline survey established in 2018. The participants in this study were selected only from Hebei Province only. A total of two urban areas, two suburban areas, two townships, and one village were randomly selected from two cities (i.e., Shijiazhuang and Tangshan) and two counties (i.e., Cangzhou and Xingtai). A total of 6720 people participated in the survey, of which 3254 people were aged 60 years and above. Participants with incomplete data regarding SBs $(n=547)$ and vague answers to the depression questionnaire $(n=28)$ were excluded from the analyses. The remaining 2679 participants were included in the current study. Compared with the included participants, the excluded participants had higher depressive symptoms and lower domestic work, physical exercise, and body mass index (BMI) levels (Supplementary Table 1). All personnel involved in data collection were adequately trained before the commencement of fieldwork.

\section{SBs}

SBs were measured using a questionnaire from the China Health and Nutrition Survey. The survey questionnaire was designed by an interdisciplinary group of social and biomedical scientists with extensive experience in survey research and construction related to their respective fields. The SBs in this questionnaire have been reported in other studies $[44,45]$. The participants reported the average hours each day during the week and on weekends that they were sitting and engaged in in four activities: watching TV, using the internet, reading (books, newspapers, and magazines), and social SBs (e.g., communicating with others and playing chess). Based on previous findings [24, 31, 32], watching TV was classified as a passive $\mathrm{SB}$, whereas the others were classified as mentally active SBs. The average daily hours spent on a particular sedentary activity was calculated as ([time spent on a particular sedentary activity time on the weekday $\times 5]+[$ time spent on a particular sedentary activity on the weekend $\times 2]$ )/7. With reference to previous findings $[34,46,47]$, the time spent on passive SBs was categorized into five groups $(0,0$ to $\leq 1,1$ to 2,2 to 3 , and $>3 \mathrm{~h}$ per day), and the time spent on mentally active SBs was categorized into three groups $(0,0$ to $\leq 1$, and $>1 \mathrm{~h}$ per day).

These different kinds of mentally active SBs might have distinct associations with depression. The Internet use and social SBs were categorized into three groups $(0,0$ to $\leq 1$, and $>1 \mathrm{~h}$ per day). Reading was categorized into three groups ( 0,0 to $\leq 0.5$, and $>0.5 \mathrm{~h}$ per day).

\section{Depression}

Depression was assessed using the Geriatric Depression Scale (GDS-30), which consisted of 30 items with $0-1$ points for each item [48]. The GDS-30 has been used in previous studies [49-51]. The total score could range from 0 to 30 points, and the cut-off value was 11 . A score $<11$ indicated no depressive symptoms and a score $\geq 11$ indicated depressive symptoms. Most previous studies used 11 as the cut-off value [41, 52, 53]. A GDS-30 validity survey in a large Chinese ageing population found that with 11 as the cut-off value, the KuderRichardson coefficients for a cognitively normal elderly group, a mild cognitive impairment screening group, and the whole population were $0.834,0.821$, and 0.840 , respectively [41]. Other studies have also demonstrated the instrument's validity [54-56].

\section{Covariates}

The analyses were adjusted for covariates including sex, age, education, employment (yes/ no), smoking, alcohol consumption in the previous year (2017), 
sleep duration, domestic work, physical exercise, BMI, and chronic diseases [22, 32-34]. Height was measured using a stable stadiometer (Seca, Germany) with $0.1 \mathrm{~cm}$ precision, and the participants were required to remove their shoes. Weight was measured using an electronic scale with $0.5 \mathrm{~kg}$ precision, and participants were asked to remove their shoes and minimize clothing. BMI was calculated by dividing body weight in $\mathrm{kg}$ by height squared in $\mathrm{m}^{2}$. BMI was divided into two groups $\left(<24\right.$ and $\left.\geq 24 \mathrm{~kg} / \mathrm{m}^{2}\right)$ following the Guidelines for the Prevention and Control of Overweight and Obesity in Chinese Adults (2003).

Physical exercise and domestic work were measured using the China Health and Nutrition Survey questionnaire that has been reported in other studies $[57,58]$. The participants reported the average hours each day during the week and on weekends that they engaged in a particular sport (including martial arts; running or swimming; gymnastics, dancing, or acrobatics; walking, football, basketball, or tennis; table tennis or tai chi). Investigators also asked the participants how much domestic work (including buying food, cooking, doing laundry, washing or ironing clothes by using hands, and cleaning rooms) they did each day. According to the Compendium of Physical Activities [59] and a previous study [60], physical exercise and domestic work were assessed against general or moderate criteria, and METs/hour were estimated as follows: 10.0 for martial arts; 7.0 for running or swimming; 4.5 for gymnastics, dancing, or acrobatics; 3.5 for walking; 7.0 for playing football, basketball, or tennis; 3.75 for playing badminton or volleyball; 4.0 for playing table tennis or tai chi; 2.3 for buying food; 2.25 for cooking; 2.0 for doing laundry; 2.3 for washing or ironing clothes with hands; and 3.0 for cleaning rooms. The MET-hours/ day for each particular sport or type of domestic work was calculated as (specific sport/domestic work time $x$ hours spent per day).

Measures of other covariates, including sex, age ( $\leq$ $65,65-70,70-75,>75$ years), education (primary and below or secondary and above), employment (yes or no), smoking (current/previous smoking or nonsmoking), alcohol consumption (yes or no) in the previous year (2017), sleep duration ( $\leq 6,6$ to 9 , or $\geq 9 \mathrm{~h}$ ), and chronic diseases $(0,1$, or $\geq 2)$, were obtained by conducting a face-to-face interview. Chronic diseases included hypertension, diabetes, myocardial infarction, and stroke; each was assigned a score of 1 for a total score range of $0-4$ points. Higher scores indicated more chronic diseases [7]. The history of the disease was determined by asking the participants whether their doctor had given them a particular disease diagnosis.

\section{Statistical analysis}

Continuous variables are presented as the mean \pm standard deviation, and categorical variables are expressed as percentages (\%). Chi-squared tests for categorical variables and $t$ tests or Wilcoxon rank tests for continuous variables were performed to compare the depression and nondepression groups. Multivariable logistic regression analyses were used to estimate odds ratios (ORs) with 95\% confidence intervals (CIs) for the association between depression and SBs (passive and mentally active SBs). In all models, the reference group for passive SBs was $1-2 h$, and that for mentally active SBs was $0 h$. Three models were built. Model 1 adjusted for sex, age, education, work, smoking, alcohol consumption, BMI, and chronic diseases. Next, Model 2 adjusted Model 1 covariates and sleep duration, domestic work, and physical exercise. Finally, Model 3 adjusted Model 2 covariates and the other category of SBs (for example, adjusted for mentally active SBs when exploring the relationship between passive SBs and depression).

To explore different mentally positive SBs that might increase the risk of depression, we analysed the relationship between depression and using the internet, reading, and other SBs. Multivariable logistic regression analyses were used, and the reference group for internet use, reading, and other SBs was $0 \mathrm{~h}$ in all models. Model 1 and Model 2 were adjusted as described above. Model 3 adjusted Model 2 covariates and each other type of SBs (for example, adjusted for passive SBs, reading, and social SBs when exploring the relationship between using the internet and depression).

Considering that missing values among the covariate measures might influence the results, a sensitivity analysis was conducted to investigate the association between $\mathrm{SB}$ types and depression after removing variables containing missing values.

Statistical significance was set at two-sided $p<0.05$. All analyses were performed using the $\mathrm{R}$ software (version 4.0.0).

\section{Results}

Sample characteristics are presented in Table 1. Of the 2679 participants, 139 (5.19\%) had depression. Compared with the participants who scored high on the GDS30 scale, the participants who scored low were older, smoked less, consumed less energy with domestic work and physical exercise, spent more time on passive SBs, and had lower BMI.

Table 2 displays the association of passive SBs and mentally active SBs with depression. After the final model adjustment, depression was associated with 3.59 (95\% CI $=1.93-6.68)$ times higher odds among participants who spent 3 or more hours on passive SBs and 
Table 1 Characteristics of the study sample

\begin{tabular}{|c|c|c|c|}
\hline & $\begin{array}{l}\text { Non-depression } \\
n=2540\end{array}$ & $\begin{array}{l}\text { Depression } \\
n=139\end{array}$ & $p$ value $^{a}$ \\
\hline \multicolumn{4}{|l|}{ Age (years) } \\
\hline$\leq 65$ & $763(30.0)$ & $34(24.5)$ & $0.030^{*}$ \\
\hline $65-70$ & $639(25.2)$ & $25(18.0)$ & \\
\hline $70-75$ & $646(25.4)$ & $44(31.7)$ & \\
\hline$>75$ & $492(19.4)$ & $36(25.8)$ & \\
\hline \multicolumn{4}{|l|}{ Sex } \\
\hline Men & $1096(43.1)$ & $50(36.0)$ & 0.115 \\
\hline Women & $1444(56.9)$ & $89(64.0)$ & \\
\hline \multicolumn{4}{|l|}{ Smoke } \\
\hline Current/Previous & $127(16.2)$ & $11(8.0)$ & $0.014^{*}$ \\
\hline Never & $2125(83.8)$ & $411(92.0)$ & \\
\hline \multicolumn{4}{|l|}{ Drink (2017) } \\
\hline No & $2135(84.3)$ & $123(89.1)$ & 0.158 \\
\hline Yes & $398(15.7)$ & $15(10.9)$ & \\
\hline \multicolumn{4}{|l|}{ Education } \\
\hline Primary and below & $1628(64.3)$ & $92(68.1)$ & 0.416 \\
\hline Secondary and above & $903(35.7)$ & $43(31.9)$ & \\
\hline \multicolumn{4}{|l|}{ Employment } \\
\hline Yes & $131(8.7)$ & $8(5.8)$ & 0.299 \\
\hline No & $2320(91.3)$ & $220(94.2)$ & \\
\hline \multicolumn{4}{|l|}{ Chronic diseases ${ }^{b}$} \\
\hline 0 & $1466(58.0)$ & $74(55.7)$ & \\
\hline 1 & $860(34.0)$ & $45(33.8)$ & 0.570 \\
\hline 2 & $202(8.0)$ & $14(10.5)$ & \\
\hline Domestic work (MET-h/d) & $3.9 \pm 3.7$ & $3.1 \pm 3.5$ & $0.021^{*}$ \\
\hline Physical exercise (MET-h/d) & $2.2 \pm 3.7$ & $1.7 \pm 3.3$ & $0.017^{*}$ \\
\hline \multicolumn{4}{|l|}{ Passive SBs (h/d) } \\
\hline$=0$ & $450(17.7)$ & $37(26.6)$ & $<0.001^{*}$ \\
\hline$>0-\leq 1$ & $654(25.7)$ & $23(16.5)$ & \\
\hline $1-2$ & $842(33.1)$ & $27(19.4)$ & \\
\hline $2-3$ & $330(13.0)$ & $26(18.7)$ & \\
\hline$>3$ & $264(10.4)$ & $26(18.7)$ & \\
\hline \multicolumn{4}{|l|}{ Mentally active SBs (h/d) } \\
\hline$=0$ & $1944(76.5)$ & $116(83.5)$ & $0.010^{*}$ \\
\hline$>0-\leq 1$ & $236(9.3)$ & $15(10.8)$ & \\
\hline$>1$ & $360(14.2)$ & $8(5.7)$ & \\
\hline \multicolumn{4}{|l|}{ Sleep duration (h/d) } \\
\hline$\leq 6$ & $744(29.3)$ & $52(37.4)$ & 0.088 \\
\hline $6-9$ & $1594(62.8)$ & $80(57.6)$ & \\
\hline$\geq 9$ & $200(7.9)$ & $7(5.0)$ & \\
\hline \multicolumn{4}{|l|}{ BMI $\left(\mathrm{kg} / \mathrm{m}^{2}\right)$} \\
\hline$<24$ & $929(39.9)$ & $68(51.9)$ & $0.008^{*}$ \\
\hline$\geq 24$ & $1400(60.1)$ & $63(48.1)$ & \\
\hline
\end{tabular}

$B M I$, body mass index

Covariates were missing for BMI $(n=200)$, education $(n=13)$, smoke $(n=5)$, drink $(n=8)$, chronic diseases $(n=16)$, domestic work $(n=144)$, physical exercise $(n=14)$, sleep $(n=2)$

${ }^{\text {a }}$ Values are means \pm SDs or $\mathrm{n}(\%)$. The difference in sample characteristics was tested by Chi-squared tests and t-tests or Wilcoxon rank test for categorical and continuous variables respectively
Table 1 (continued)

${ }^{\mathrm{b}}$ Chronic diseases included hypertension, diabetes, myocardial infarction, and stroke, each of which was assigned a score of 1

${ }^{*} p<0.05$

2.21 (95\% CI $=1.16-4.16)$ times higher odds among participants who spent $2-3 \mathrm{~h}$ in comparison with those who spent $1-2 \mathrm{~h}$ on passive SBs. The participants who spent $0 \mathrm{~h}$ on passive SBs had an increased risk of depression compared to those who spent $1-2 \mathrm{~h}$ (adjusted $\mathrm{OR}=2.09$, $95 \% \mathrm{CI}=1.18-3.76$ ). The participants who spent $>1 \mathrm{~h}$ on mentally active SBs had a decreased risk of depression (adjusted $\mathrm{OR}=0.24,95 \% \mathrm{CI}=0.06-0.67$ ) compared with those without mentally active SBs after the final model adjustment.

Compared with the participants who did not participate in social SBs, the participants who spent $>1 \mathrm{~h}$ had a decreased risk of depression (adjusted for OR $=0.24,95 \%$ $\mathrm{CI}=0.06-0.66)$ after the final model adjustment. Spending more than $0.5 \mathrm{~h}$ on reading (adjusted $\mathrm{OR}=1.09,95 \%$ $\mathrm{CI}=0.32-2.86)$ and more than one hour on using the internet (adjusted OR $=1.12,95 \% \mathrm{CI}=0.31-3.08$ ) had no association with depression compared with participants who did not take part in these activities after the final model adjustment (Table 3).

The sensitivity analysis results are presented in supplemental tables (Supplementary Tables 2-4). The participants with incomplete covariate data were excluded, and 2291 participants were eventually included. The logistic regression analysis with these participants found that the results did not change.

\section{Discussion}

This study found a positive correlation between prolonged TV viewing (a passive $\mathrm{SB}$ ) and depression, and this finding was consistent with those in previous studies [21, 33, 47]. Hamer et al. performed a cross-sectional study and found that TV viewing time ( $\geq 6 \mathrm{~h}$ vs. $<2 \mathrm{~h}$ ) was associated with high depressive symptoms $(\beta=0.49,95 \% \mathrm{CI}=0.63-0.35)$ [33]. Another cross-sectional study was conducted among 42,469 people in low- and middle-income countries, including 14,585 older adults over 65 years old [21]. In this older group, those who watched TV for 8 or more hours had a 1.72-fold increased risk of depression than those who watched TV for less than $8 \mathrm{~h}$ a day. A study also found that women who spent 21 or more hours/week watching TV had a 1.13-fold increased risk of depression than those who spent $0-1 \mathrm{~h} /$ week among 49,821 older American women from the Nurses' Health study who were followed over 10years [47]. Several mechanisms could explain the relationship between TV watching and depression. First, older persons experience reduced social 
Table 2 Associations between depression and sedentary behaviors (SBs) assessed by multivariable logistic

\begin{tabular}{|c|c|c|c|c|c|c|}
\hline & \multicolumn{2}{|l|}{ Model 1} & \multicolumn{2}{|l|}{ Model 2} & \multicolumn{2}{|l|}{ Model 3} \\
\hline & OR $(95 \% \mathrm{Cl})$ & $p$ value & OR $(95 \% \mathrm{Cl})$ & $p$ value & OR $(95 \% \mathrm{Cl})$ & $p$ value \\
\hline \multicolumn{7}{|c|}{ Passive SBs (h/d) } \\
\hline$=0$ & $2.49(1.46,4.33)$ & $0.001^{*}$ & $1.99(1.12,3.57)$ & 0.019 & $2.09(1.18,3.76)$ & $0.012^{*}$ \\
\hline$>0-\leq 1$ & $0.96(0.51,1.78)$ & 0.899 & $0.98(0.52,1.84)$ & 0.955 & $0.93(0.49,1.75)$ & 0.829 \\
\hline $1-2$ & Ref & & Ref & & Ref & \\
\hline $2-3$ & $2.55(1.39,4.64)$ & $0.002^{*}$ & $2.21(1.16,4.15)$ & 0.014 & $2.21(1.16,4.16)$ & $0.014^{*}$ \\
\hline$>3$ & $3.62(2.01,6.53)$ & $<0.001^{*}$ & $3.51(1.89,6.51)$ & $<0.001^{*}$ & $3.59(1.93,6.68)$ & $<0.001^{*}$ \\
\hline \multicolumn{7}{|c|}{ Mentally active SBs (h/d) } \\
\hline$=0$ & Ref & & Ref & & Ref & \\
\hline$>0-\leq 1$ & $1.05(0.54,1.87)$ & 0.880 & $1.22(0.61,2.28)$ & 0.550 & $1.54(0.74,2.94)$ & 0.219 \\
\hline$>1$ & $0.38(0.16,0.78)$ & $0.016^{*}$ & $0.46(0.19,0.96)$ & 0.059 & $0.26(0.06,0.71)$ & $0.024^{*}$ \\
\hline
\end{tabular}

Model 1 adjusted for sex, age, education, employment, smoking, alcohol consumption in the past year, body mass index, chronic diseases

Model 2 adjusted Model 1 covariates and sleep duration, domestic work and physical exercise

Model 3 adjusted Model 2 covariates and the other category of SBs (for example, adjusted for mentally active SBs when exploring the relationship between passive SBs and depression)

${ }^{*} p<0.05$

Table 3 Associations between depression and different sedentary mentally active behaviors (SBs) assessed by multivariable logistic

\begin{tabular}{|c|c|c|c|c|c|c|}
\hline & \multicolumn{2}{|l|}{ Model 1} & \multicolumn{2}{|l|}{ Model 2} & \multicolumn{2}{|l|}{ Model 3} \\
\hline & OR $(95 \% \mathrm{Cl})$ & $p$ value & OR $(95 \% \mathrm{Cl})$ & $p$ value & OR $(95 \% \mathrm{Cl})$ & $p$ value \\
\hline \multicolumn{7}{|c|}{ Using the internet $(\mathrm{h} / \mathrm{d})$} \\
\hline$=0$ & Ref & & Ref & & Ref & \\
\hline$>0-\leq 1$ & $0.24(0.01,1.13)$ & 0.164 & $0.34(0.02,1.60)$ & 0.287 & $0.30(0.02,1.48)$ & 0.248 \\
\hline$>1$ & $1.17(0.34,3.04)$ & 0.777 & $1.38(0.40,3.70)$ & 0.560 & $1.12(0.31,3.08)$ & 0.842 \\
\hline \multicolumn{7}{|c|}{ Reading (h/d) } \\
\hline$=0$ & Ref & & Ref & & Ref & \\
\hline$>0-\leq 0.5$ & $0.60(0.10,2.03)$ & 0.494 & $0.78(0.12,2.69)$ & 0.743 & $0.65(0.10,2.34)$ & 0.576 \\
\hline$>0.5$ & $0.84(0.25,2.12)$ & 0.743 & $1.09(0.32,2.81)$ & 0.870 & $1.09(0.32,2.86)$ & 0.874 \\
\hline \multicolumn{7}{|c|}{ Social SBs (h/d) } \\
\hline$=0$ & Ref & & Ref & & Ref & \\
\hline$>0-\leq 1$ & $1.44(0.59,3.03)$ & 0.371 & $1.42(0.53,3.18)$ & 0.439 & $1.56(0.57,3.59)$ & 0.340 \\
\hline$>1$ & $0.23(0.06,0.62)$ & $0.013^{*}$ & $0.27(0.06,0.74)$ & 0.028 & $0.24(0.06,0.66)$ & $0.017^{*}$ \\
\hline
\end{tabular}

Model 1 adjusted for sex, age, education, employment, smoking, alcohol consumption in the past year, body mass index, chronic diseases

Model 2 adjusted Model 1 covariates and sleep duration, domestic work and physical exercise

Model 3 adjusted Model 2 covariates and each other type of SBs (for example, adjusted for passive SBs, reading books and newspaper, and other SBs when exploring the relationship between using the Internet and depression)

${ }^{*} p<0.05$

support, increased social isolation, and increased loneliness due to changes in living circumstances [61]. Watching TV, the main way to compensate for the loss of social connections, increases loneliness [30]. Loneliness can lead to socially ineffective, passive, and negative attitudes towards the self and others and a sense of hopelessness, and loneliness has been closely associated with depression [62]. Second, a systematic review showed that prolonged engagement in SBs increases levels of inflammatory cytokines [63]. Inflammation is one of the main pathways leading to depression [64].

The present study indicated that spending no time on passive SBs was associated with increased depression. A cross-sectional survey based on 60,202 adults from Brazil's National Health Survey showed similar results and found that less than $1 \mathrm{~h}$ of TV viewing was associated with increased depression [46]. However, this association was not found among older adults in the stratified 
analysis by age. A Brazilian study found that people who watched less TV were more likely to be without a degree. Not having a degree has been associated with low socioeconomic status, which has been associated with depression. Although the present study found a higher prevalence of having primary school and below among the participants with depression risk and low TV viewing, a similar result was also found among the participants with depression risk and high TV viewing (0: $78.4 \%, 0$ to $\leq 1 \mathrm{~h}: 38.1 \%, 1$ to $2 \mathrm{~h}: 56.0 \%, 2$ to $3 \mathrm{~h}: 80.8 \%$, and $\geq 3 \mathrm{~h}: 76.9 \% ; p=0.031$ ). Therefore, the lack of TV viewing might not have been a measure-of-proxy for a low socioeconomic status in this study. The high risk of depression among the participants who did not watch TV might have been linked to the apathy associated with depression. As a prominent symptom of depression in older adults [65], apathy manifests as lack of interest and emotional flatness [66], causing the elderly individuals to lose interest in watching TV. One study also showed that participants with major depression watched less TV than participants without a diagnosis of major depression [34]. The present study also found that $26.7 \%$ of participants with depressive symptoms did not watch TV at all.

Our results suggested that engaging in mentally active SBs (predominantly social SBs) could decrease the risk of depression. A previous study found a negative correlation between social SBs and psychological stress [67]. Social SBs, such as interacting with others and playing chess, are good ways to build social connections and prevent depression. However, reading or using the internet had no association with depression in this study. A crosssectional study found that participants using the internet reported low depressive symptoms $(\beta=-0.58,95 \%$ $\mathrm{CI}=-0.50$ to -0.66 ), but their longitudinal study did not find such an association [33]. Another study found only that SBs (such as reading, using the computer, and commuting) have a protective effect on depression in women and not in men [32]. Few speculations about the link between these two factors have been were put forward. First, some studies have suggested that using the internet and reading can improve cognitive function [26, 27 ] and that TV viewing can increase the risk of cognitive dysfunction [26]. Therefore, one study speculated that certain mentally positive SBs might counterbalance the adverse effects of harmful sitting on the brain and mental health [32]. However, whether this prediction is correct and the specific underlying mechanisms need further research. Second, another study found that using the internet to compensate for social isolation was associated with a reduced risk of depression in older adults [28]. A study conducted with older Chinese adults also found that internet use can improve life satisfaction [68].
Therefore, increased social interactions in older adults (including internet use, communicating with others, and playing chess) appear to reduce the risk of depression.

\section{Strengths and limitations}

The strengths of this study are as follows. First, this study explored the associations between different types of SBs and depression. Second, few studies have adjusted for sleep duration and domestic work as confounders. As part of daily life, sleep duration and domestic work affected the relationship between SBs and depression.

This study had some limitations. First, this study was a cross-sectional study and could not determine the direction of the relationships between SBs and depression. Second, the study used self-reported SBs, which could introduced bias. Future research using tools, such as accelerometers, which can objectively measure sedentary time, is recommended. Third, the GDS-30, a self-assessed depression screening tool, does not represent a clinical diagnosis and may result in a certain number of false-positive and false-negative results. An international diagnostic interview or semiquantitative scale is suggested to be used to diagnose depression. Fourth, although we adjusted for multiple confounding variables, the effects of residual or other unknown confounding factors cannot be excluded. Finally, although this study explored the associations between time spent on passive SBs and depression, this association cannot be generalized to other types of SBs.

\section{Conclusions}

This cross-sectional study showed that spending two or more hours/day on passive SBs (e.g., watching TV) seems to be associated with a high risk for depression among people aged 60 years and older in Hebei Province, China. Mentally active SBs (predominantly social SBs) could reduce the risk of depression. Some participants with depression probably did not watch TV. These findings suggest that spending more time on social SBs (such as communicating with others and playing chess) rather than watching TV may have important public health implications for preventing and managing depression among older Chinese adults. Moreover, society should attend to the mental health of elderly adults who do not watch TV, and they may be more prone to suffer from depressive symptoms.

\section{Abbreviations}

SBs: Sedentary behaviors; METs: Metabolic equivalents; GDS-30: Geriatric Depression Scale; AD: Alzheimer's disease; PD: Parkinson's disease; ORs: Odds ratios; Cls: Confidence intervals; BMl: Body mass index. 


\section{Supplementary Information}

The online version contains supplementary material available at https://doi. org/10.1186/s12889-022-12727-7.

Additional file 1: Supplementary Table 1. The characteristics of the participants excluded. Supplementary Table 2. Characteristics of the study sample. Supplementary Table 3. Associations between depression and sedentary behaviors (SBS) assessed by multivariable logistic. Supplementary Table 4. Associations between depression and different mentally active sedentary behaviors (SBs) assessed by multivariable logistic.

\section{Acknowledgments}

The authors are very grateful to all the participants in this study.

\section{Authors' contributions}

Jiaqi Wang made the conceptualization of the study, data proceeding, statistical procedures, and wrote the first draft. Ruigiang Li made the conceptualization of the study and statistical procedures. Yuxia Ma made the funding acquisition and project administration. Limin Zhang, Xian Gao, Meiqi Zhou, and Xinjing Zhang provided critical comments and approved the final manuscript.

\section{Funding}

This research was supported by the Ministry of Finance of China, the National Key R\&D Program of China, Precision Medicine Project-Cohort Study on Nervous System Diseases (2017YFC0907700), Community-based Cohort Study on Nervous System Diseases (2017YFC0907701). All funders had no role in the design, analysis, or writing of this article.

\section{Availability of data and materials}

The data that support the findings of this study are available from the corresponding author upon reasonable request.

\section{Declarations}

\section{Ethics approval and consent to participate}

The study was conducted in accordance with the guidelines established by the Declaration of Helsinki. Written informed consent was obtained for each participant before the survey. All data collected was treated and analyzed confidentially. The protocol of this study was reviewed and approved by the Institutional Review Board of the National Institute for Nutrition and Health (No. 2017020, 6 November 2017).

\section{Consent for publication}

Not applicable.

\section{Competing interests}

The authors report no conflict of interest.

\section{Author details}

${ }^{1}$ Department of Nutrition and Food Hygiene, School of Public Health, Hebei Medical University, Hebei Province Key Laboratory of Environment and Human Health, Shijiazhuang, China. ${ }^{2}$ Circulating Chemical Industry Park Hospital, The First Hospital of Hebei Medical University, Shijiazhuang, China.

Received: 29 September 2021 Accepted: 7 February 2022 Published online: 11 February 2022

\section{References}

1. Ferrari AJ, Charlson FJ, Norman RE, Patten SB, Freedman G, Murray CJL, et al. Burden of depressive disorders by country, sex, age, and year: findings from the global burden of disease study 2010. PLoS Med. 2013;10(11):e1001547.

2. Organization WH. Depression and other common mental disorders; 2017.

3. Lett HS, Blumenthal JA, Babyak MA, Sherwood A, Strauman T, Robins C, et al. Depression as a risk factor for coronary artery disease: evidence, mechanisms, and treatment. Psychosom Med. 2004;66(3):305-15.
4. Musselman DL, Betan E, Larsen H, Phillips LS. Relationship of depression to diabetes types 1 and 2: epidemiology, biology, and treatment. Biol Psychiatry. 2003;54(3):317-29.

5. Takeuchi T, Nakao M, Nomura K, Inoue M, Tsurugano S, Shinozaki Y, et al. Association of the metabolic syndrome with depression and anxiety in Japanese men: a 1-year cohort study. Diabetes Metab Res Rev. 2009;25(8):762-7.

6. Pate RR, O'Neill JR, Lobelo F. The evolving definition of "sedentary". Exerc Sport Sci Rev. 2008:36(4):173-8.

7. Jefferis BJ, Sartini C, Shiroma E, Whincup PH, Wannamethee SG, Lee IM. Duration and breaks in sedentary behaviour: accelerometer data from 1566 community-dwelling older men (British regional heart study). Br J Sports Med. 2015:49(24):1591-4.

8. Shiroma EJ, Freedson PS, Trost SG, Lee I-M. Patterns of accelerometerassessed sedentary behavior in older women. JAMA. 2013;310:2562-3.

9. Ford ES, Caspersen CJ. Sedentary behaviour and cardiovascular disease: a review of prospective studies. Int J Epidemiol. 2012;41 (5):1338-53.

10. Hamilton MT, Hamilton DG, Zderic TW. Sedentary behavior as a mediator of type 2 diabetes. Medicine Sport Sci. 2014;60:11-26.

11. Lynch BM. Sedentary behavior and cancer: a systematic review of the literature and proposed biological mechanisms. Cancer Epidemiol Biomark Prev. 2010;19(11):2691-709.

12. Kerr J, Anderson C, Lippman SM. Physical activity, sedentary behaviour, diet, and cancer: an update and emerging new evidence. Lancet Oncol. 2017;18(8):E457-71.

13. Kim Y, Wilkens LR, Park SY, Goodman MT, Monroe KR, Kolonel LN. Association between various sedentary behaviours and all-cause, cardiovascular disease and cancer mortality: the multiethnic cohort study. Int J Epidemiol. 2013:42(4):1040-56.

14. Patterson R, McNamara E, Tainio M. Sedentary behaviour and risk of allcause, cardiovascular and cancer mortality, and incident type 2 diabetes: a systematic review and dose response meta-analysis. Eur J Epidemiol. 2018:33:811-29.

15. Teychenne M, Ball K, Salmon J. Sedentary behavior and depression among adults: a review. Int J Behavior Med. 2010;17(4):246-54.

16. Huang YC, Li LQ, Gan Y, Wang C, Jiang H, Cao SY, et al. Sedentary behaviors and risk of depression: a meta-analysis of prospective studies. Transl Psychiatry. 2020;10(1):26.

17. Teychenne M, Costigan SA, Parker K. The association between sedentary behaviour and risk of anxiety: a systematic review. BMC Public Health. 2015;15:513.

18. Allen MS, Walter EE, Swann C. Sedentary behaviour and risk of anxiety: a systematic review and meta-analysis. J Affect Disord. 2019;242:5-13.

19. Lampinen P, Heikkinen E. Reduced mobility and physical activity as predictors of depressive symptoms among community-dwelling older adults: an eight-year follow-up study. Aging Clin Exp Res. 2003;15(3):205-11.

20. Tsutsumimoto K, Makizako H, Doi T, Hotta R, Nakakubo S, Shimada H, et al. Prospective associations between sedentary behaviour and incident depressive symptoms in older people: a 15-month longitudinal cohort study. Int J Geriatr Psychiatry. 2017:32(2):193-200.

21. Stubbs B, Vancampfort D, Firth J, Schuch FB. Relationship between sedentary behavior and depression: a mediation analysis of influential factors across the lifespan among 42,469 people in low- and middle-income countries. J Affect Disord. 2018:229:231-8.

22. Eriksson $M$, Nääs S, Berginström N, Nordström P, Hansson P, Nordström A. Sedentary behavior as a potential risk factor for depression among 70-year-olds. J Affect Disord. 2020;263:605-8.

23. Vancampfort D, Hallgren M, Schuch F, Stubbs B, Smith L, Rosenbaum S, et al. Sedentary behavior and depression among community-dwelling adults aged $>/=50$ years: results from the irish longitudinal study on ageing. J Affect Disord. 2020;262:389-96.

24. Hallgren M, Thi-Thuy-Dung N, Owen N, Stubbs B, Vancampfort D, Lundin $A$, et al. Cross-sectional and prospective relationships of passive and mentally active sedentary behaviours and physical activity with depression. $\mathrm{Br}$ J Psychiatry. 2020:217(2):413-9.

25. Hallgren M, Owen N, Stubbs B, Zeebari Z, Vancampfort D, Schoch F, et al. Passive and mentally-active sedentary behaviors and incident major depressive disorder: a 13-year cohort study. J Affect Disord. 2018;241:579-85. 
26. Kesse-Guyot E, Charreire H, Andreeva VA, Touvier M, Hercberg S, Galan $P$, et al. Cross-sectional and longitudinal associations of different sedentary behaviors with cognitive performance in older adults. PLoS One. 2012;7(10):e47831.

27. Wang JYJ, Zhou DHD, Li J, Zhang M, Deng J, Tang M, et al. Leisure activity and risk of cognitive impairment: the Chongqing aging study. Neurology. 2006;66(6):911-3.

28. Cotten SR, Ford G, Ford S, Hale TM. Internet use and depression among retired older adults in the United States: a longitudinal analysis. J Gerontol Ser B-Psychol Sci Soc Sci. 2014;69(5):763-71.

29. Cotten SR, Anderson WA, McCullough BM. Impact of internet use on loneliness and contact with others among older adults: cross-sectional analysis. J Med Internet Res. 2013;15(2):e39.

30. Fingerman KL, Kim YK, Ng YT, Zhang S, Huo M, Birditt KS. Television viewing, physical activity, and loneliness in late life. The Gerontologist. 2021;gnab120.

31. Kikuchi H, Inoue S, Sugiyama T, Owen N, Oka K, Nakaya T, et al. Distinct associations of different sedentary behaviors with health-related attributes among older adults. Prev Med. 2014;67:335-9.

32. Andrade-Gomez E, Martinez-Gomez D, Rodriguez-Artalejo F, GarciaEsquinas E. Sedentary behaviors, physical activity, and changes in depression and psychological distress symptoms in older adults. Depress Anxiety. 2018;35(9):884-97.

33. Hamer M, Stamatakis E. Prospective study of sedentary behavior, risk of depression, and cognitive impairment. Med Sci Sports Exerc. 2014;46(4):718-23.

34. Da Ronch C, Canuto A, Volkert J, Massarenti S, Weber K, Dehoust MC, et al. Association of television viewing with mental health and mild cognitive impairment in the elderly in three European countries, data from the MentDis_ICF65+ project. Ment Health Phys Act. 2015;8:8-14.

35. Rosenberg DE, Bellettiere J, Gardiner PA, Villarreal VN, Crist K, Kerr J. Independent associations between sedentary behaviors and mental, cognitive, physical, and functional health among older adults in retirement communities. J Gerontol A Biol Sci Med Sci. 2016;71(1):78-83.

36. Gautam R, Saito T, Kai I. Leisure and religious activity participation and mental health: gender analysis of older adults in Nepal. BMC Public Health. 2007;7:299.

37. Wang KT, Fu SH, Hsieh PL, Lin YL, Yang SY. Investigating the relationship between media usage, depression, and quality of life among older adults. Healthcare. 2021;9(9):1154.

38. Wilmore MJ. Gatekeepers of cultural memory: televising religious rituals in Tansen, Nepal. Ethnos. 2006;71(3):317-42.

39. Li D, Zhang DJ, Shao JJ, Qi XD, Tian L. A meta-analysis of the prevalence of depressive symptoms in Chinese older adults. Arch Gerontol Geriatr. 2014;58(1):1-9.

40. Ding CC, Feng GY, Yuan F, Gong WY, Yao YC, Ma YN, et al. Temporal trends and recent correlates in sedentary behaviors among Chinese adults from 2002 to 2010-2012. Int J Environ Res Public Health. 2020:17(1):158.

41. Huang FF, Wang HJ, Wang ZH, Zhang JG, Du WW, Jia XF, et al. Is geriatric depression scale a valid instrument to screen depression in Chinese community-dwelling elderly? BMC Geriatr. 2021:21(1):310.

42. Huang QM, Jia XF, Zhang JG, Huang FF, Wang HJ, Zhang B, et al. Dietcognition associations differ in mild cognitive impairment subtypes. Nutrients. 2021;13(4):1341

43. Jia XF, Wang ZH, Huang FF, Su C, Du WW, Jiang HR, et al. A comparison of the mini-mental state examination (MMSE) with the Montreal cognitive assessment (MoCA) for mild cognitive impairment screening in Chinese middle-aged and older population: a cross-sectional study. BMC Psychiatry. 2021;21(1):485.

44. Dong W, Gao J, Zhou Z, Bai R, Wu Y, Su M, et al. Effects of China's urban basic health insurance on preventive care service utilization and health behaviors: evidence from the China health and nutrition survey. PLoS One. 2018;13(12):e0209890.

45. Wang Y, Su C, Ouyang Y-F, Jia X-F, Zhang B, Wang Z-H, et al. Secular trends in sedentary behaviors and associations with weight indicators among Chinese reproductive-age women from 2004 to 2015: findings from the China health and nutrition survey. Int J Obes. 2020;44(11):2267-78.

46. Werneck AO, Oyeyemi AL, Szwarcwald CL, Vancampfort D, Silva DR. Associations between TV viewing and depressive symptoms among 60,202 Brazilian adults: the Brazilian national health survey. J Affect Disord. 2018:236:23-30
47. Lucas M, Mekary R, Pan A, Mirzaei F, O'Reilly EJ, Willett WC, et al. Relation between clinical depression risk and physical activity and time spent watching television in older women: a 10-year prospective follow-up study. Am J Epidemiol. 2011;174(9):1017-27.

48. Brink TL, Yesavage JA, Lum O, Heersema PH, Adey M, Rose TL. Screening tests for geriatric depression. Clin Gerontol. 1982;1 (1):37-43.

49. Liang Y, Li XH, Yang TT, Li MY, Ruan Y, Yang YH, et al. Patterns of physical activity and their relationship with depression among community-dwelling older adults in Shanghai, China: a latent class approach. BMC Geriatr. 2021:21(1):587.

50. Li QJ, Zhou XD, Ma S, Jiang MM, Li L. The effect of migration on social capital and depression among older adults in China. Soc Psychiatry Psychiatr Epidemiol. 2017;52(12):1513-22.

51. Rosenberg PB, Mielke MM, Xue QL, Carlson MC. Depressive symptoms predict incident cognitive impairment in cognitive healthy older women. Am J Geriatr Psychiatr. 2010;18(3):204-11.

52. Mitchell AJ, Bird V, Rizzo M, Meader N. Which version of the geriatric depression scale is Most useful in medical settings and nursing homes? Diagnostic validity meta-analysis. Am J Geriatr Psychiatr. 2010;18(12):1066-77.

53. Yesavage JA, Brink TL, Rose TL, Lum O, Huang V, Adey M, et al. Development and validation of a geriatric depression screening scale: a preliminary report. J Psychiatr Res. 1982;17(1):37-49.

54. Wancata J, Alexandrowicz R, Marquart B, Weiss M, Friedrich F. The criterion validity of the geriatric depression scale: a systematic review. Acta Psychiatr Scand. 2006;114(6):398-410.

55. Chan AC. Clinical validation of the geriatric depression scale (GDS): Chinese version. J Aging Health. 1996;8(2):238-53.

56. Chau J, Martin CR, Thompson DR, Chang AM, Woo J. Factor structure of the Chinese version of the geriatric depression scale. Psychol Health Med. 2006;11(1):48-59.

57. Zhou JM, Britigan DH, Rajaram SS, Wang HM, Su DJ. Association between leisure time physical activity preference and behavior: evidence from the China Health \& Nutrition Survey, 2004-2011. BMC Public Health. 2017:17(1):451.

58. Ng SW, Norton EC, Popkin BM. Why have physical activity levels declined among Chinese adults? Findings from the 1991-2006 China health and nutrition surveys. Soc Sci Med (1982). 2009;68(7):1305-14.

59. Ainsworth BE, Haskell WL, Whitt MC, Irwin ML, Swartz AM, Strath SJ, et al. Compendium of physical activities: an update of activity codes and MET intensities. Med Sci Sports Exerc. 2000;32(9 Suppl):S498-504.

60. Haskell WL, Lee IM, Pate RR, Powell KE, Blair SN, Franklin BA, et al. Physical activity and public health: updated recommendation for adults from the American College of Sports Medicine and the American Heart Association. Med Sci Sports Exerc. 2007;39(8):1423-34.

61. Czaja SJ, Moxley JH, Rogers WA. Social support, isolation, loneliness, and health among older adults in the PRISM randomized controlled trial. Front Psychol. 2021;12:728658.

62. Saul H, Gursul D. Loneliness is strongly linked to depression among older adults, a long term study suggests. BMJ-Brit Med J. 2021;375:n2524.

63. Wirth K, Klenk J, Brefka S, Dallmeier D, Faehling K, Figuls MRI, et al. Biomarkers associated with sedentary behaviour in older adults: a systematic review. Ageing Res Rev. 2017:35:87-111.

64. Han Q-Q, Yu J. Inflammation: a mechanism of depression? Neurosci Bull. 2014;30(3):515-23.

65. Yuen GS, Bhutani S, Lucas BJ, Gunning FM, AbdelMalak B, Seirup JK, et al. Apathy in late-life depression: common, persistent, and disabling. Am J Geriatr Psychiatr. 2015;23(5):488-94.

66. Marin RS. Differential diagnosis and classification of apathy. Am J Psychiatry. 1990;147(1):22-30.

67. Atkin AJ, Adams E, Bull FC, Biddle SJH. Non-occupational sitting and mental well-being in employed adults. Ann Behavior Med. 2012:43(2):181-8.

68. Xie L, Yang HL, Lin XY, Ti SM, Wu YY, Zhang S, et al. Does the internet use improve the mental health of Chinese older adults? Front Public Health. 2021;9:673368.

\section{Publisher's Note}

Springer Nature remains neutral with regard to jurisdictional claims in published maps and institutional affiliations. 